\title{
Body Size, Growth, and Feather Mass of the Endangered Hawaiian Moorhen (Gallinula chloropus sandvicensis) ${ }^{1}$
}

\author{
David W. DesRochers, ${ }^{2,5}$ Michael D. Silbernagle, ${ }^{3}$ Aaron Nadig, ${ }^{4}$ and 7. Michael Reed ${ }^{2}$
}

\begin{abstract}
Body and feather mass data are important in avian studies and are required for determining things such as body condition and energetic carrying capacity. There are 12 subspecies of Common Moorhens (Gallinula chloropus), six continental and six island subspecies, of which two are endangered. Body mass data for multiple individuals are available for only three subspecies, and feather mass data have been reported for only one individual. Body mass $(n=82)$ and feather mass $(n=2)$ for adults and body mass for three subadult age classes $(n=27)$ are provided for the Hawaiian subspecies of Common Moorhen (G. c. sandvicensis). Other body size measurements, including tarsus length, shield-bill length, shield width, and wing cord length also are presented. Adult Hawaiian Moorhen body mass averaged $350.7 \mathrm{~g}$ ( $\pm 50.0 \mathrm{SD}$; range, 232-522; 95\% CI, 339.8-361.6), and young birds appear to develop like young of G. c. chloropus and other Rallidae. Based on published data, G. c. sandvicensis is heavier than G. c. guami, female G. c. chloropus, and G. c. meridionalis; lighter than G. c. garmani and males of G. c. cachinnans; and similar in mass to G. c. cachinnans females, males of G. c. chloropus, and G. c. orientalis. There do not appear to be systematic differences in body mass between mainland (data for four subspecies) and island subspecies (data for three subspecies). Total mass of all feathers for two males was 16.2 and $12.1 \mathrm{~g}$, which made up $3.1 \%$ and $3.8 \%$, respectively, of their total body mass.
\end{abstract}

Body mass is a central piece of data required for many avian studies in which re-

${ }^{1}$ The U.S. Fish and Wildlife Service, Hawai'i Division of Forestry and Wildlife, Ducks Unlimited, Waimea Valley Audubon Center, Tufts Institute for the Environment, Tufts University Graduate Student Association, Manomet Center for Conservation Sciences, and the $\mathrm{Na}$ tional Science Foundation (no. DEB-0710119 to D.W.D.) supported this research. Manuscript accepted 9 June 2009.

2 Department of Biology, Tufts University, Medford, Massachusetts 02155.

${ }^{3} \mathrm{O}^{\prime}$ ahu National Wildlife Refuge Complex, U.S. Fish and Wildlife Service, 66-590 Kamehameha Highway, Room 2C, Hale'iwa, Hawai'i 96712-1484.

${ }^{4}$ Consultation and Technical Assistance Program, Pacific Islands Fish and Wildlife Office, 300 Ala Moana Boulevard, Room 3-122, Box 50088, Honolulu, Hawai'i 96850.

${ }^{5}$ Corresponding author (e-mail: DavidW .DesRochers@gmail.com).

Pacific Science (2010), vol. 64, no. 2:327-333

doi: $10.2984 / 64.2 .327$

(C) 2010 by University of Hawai'i Press

All rights reserved searchers are interested in evaluating body condition or calculating energetic carrying capacity (e.g., Guthery 1999). The ready availability of avian body mass data from Dunning (2008) has made these types of calculations more accessible. Even this large compilation does not present samples from throughout the range of many species; therefore the extent of geographic variation within species is not well documented. This is especially true for secretive and endangered species, for which few data typically are available (Wilcove et al. 1998). To this end, we report the first available body mass along with an estimate of growth and other morphological data for the endangered, endemic Hawaiian Moorhen (Gallinula chloropus sandvicensis), which is one of 12 subspecies of Common Moorhen (Taylor 1998). Knowing body mass information for Hawaiian Moorhen is valuable because it potentially can inform management decisions for this endangered subspecies by providing researchers information on individual body condition (e.g., 
DesRochers et al. 2009), which may indicate if food is limiting. In addition to reporting mass of Hawaiian Moorhen, we compare adult Hawaiian Moorhen mass with that of the other subspecies of moorhen where data are available. We also present the first data of which we are aware on feather mass for this subspecies. Feather mass data are fairly uncommon, but they could be important for determining energetic requirements across a species' entire life cycle including molt (Lindström et al. 1993).

\section{MATERIALS AND METHODS}

We captured birds using live trapping from April 2005 to February 2009 at James Campbell National Wildlife Refuge $\left(21^{\circ} 41^{\prime} \mathrm{N}\right.$, $\left.157^{\circ} 55^{\prime} \mathrm{W}\right)$ and Waimea Falls $\left(21^{\circ} 38^{\prime} \mathrm{N}\right.$, $158^{\circ} 63^{\prime} \mathrm{W}$ ), which are both on $\mathrm{O}^{\prime}$ ahu. We categorized prejuvenile birds into different age classes using plumage characteristics after Gollop and Marshall (1954). Specifically, class II chicks exhibit feather growth but still retain down, class III chicks lack down but have not obtained the full juvenal plumage, and we distinguished juveniles from class III chicks by the grayer plumage, more developed shield, and larger body size. We individually banded birds, so we were able to determine which individuals were recaptured. We weighed birds using a Pesola scale (to the nearest $1.0 \mathrm{~g}$ ), measured relaxed wing cord (not flattened) of nonmolting adults using a wing rule, and measured tarsus length and width (the widest measure at the midpoint of the tarsus) and shield + bill length (top of shield to bill tip) and maximum shield width using a digital caliper (Vernier). Length measurements were to the nearest $0.1 \mathrm{~mm}$. Because we were unable to measure young birds on a daily basis we were unable to calculate daily growth. Instead, we estimated a general growth pattern for young Hawaiian birds and also fitted mass data to a Gompertz growthfunction (sensu Starck and Ricklefs 1998) under the assumptions that heavier birds were older and that each measure of mass was representative of birds of different ages. We then calculated a growth constant for Hawaiian Moorhen and compared it with growth constants reported for other rails, including one that we calculated for G. c. chloropus from data in Karhu (1973). We searched primary and secondary literature for body mass and morphological data for the 11 other subspecies for comparison. We wanted to compare Hawaiian Moorhen body mass with that of other subspecies, but the only data available were means and associated ranges, or values from single individuals. Consequently, our statistical options were limited. For subspecies where means were reported, we compared them with our data for Hawaiian Moorhen by calculating and comparing $95 \%$ $t$-based confidence intervals (95\% CI) (Snedecor and Cochran 1989, Johnson 1999). Because we did not know standard deviation for the other subspecies for which body mass data were available, we estimated standard deviation by dividing the range by 8 and assuming that the data were normally distributed (Snedecor and Cochran 1989); body mass data were normally distributed for Hawaiian Moorhen (Shapiro-Wilk: $W=0.99, \quad P=$ 0.38 ). For subspecies where few individuals have been weighed, we calculated and compared means using the same approach. If two 95\% confidence intervals overlapped, then we concluded that the two means being compared did not differ. Using $t$-based confidence intervals is a conservative approach, but it is a more robust estimate of a distribution compared with using $Z$-scores (Snedecor and Cochran 1989).

We weighed all feathers together and separately weighed the primaries, secondaries, rectrices, and body feathers that we removed from two adult male Hawaiian Moorhen carcasses provided to us by the U.S. Geological Survey. Flight feathers were plucked and body feathers were removed by scalding the skin to soften the connective tissue before plucking. Feathers were weighed to the nearest $0.1 \mathrm{~g}$ once they were dry; bodies were donated to the Harvard Museum of Comparative Zoology.

\section{RESULTS AND DISCUSSION}

We captured and measured 82 adults, 18 juveniles, two class III chicks, and seven class 
II chicks. We included in our calculations the measurements of 20 adults that were captured more than once during the time of the study for a total of 109 measurements of adult mass (all recaptures $>30$ days apart; range, two to three captures per individual); we also included measurements of two juveniles that were captured twice ( $>30$ days apart). We were unable to identify the sex of individual birds due to limitations of working with an endangered species, and we also do not report change in mass for individuals caught more than one time because we did not selectively try to capture specific individuals to monitor mass changes over time. Adult Hawaiian Moorhen body mass averaged $350.7 \pm 50.0 \mathrm{~g}$ (mean $\pm \mathrm{SD} ;$ range, 232-522; 95\% CI, 339.8-361.6). See Table 1 for all Hawaiian Moorhen body size metrics. Change in body mass of young birds was not statistically different from the straight line, $y=6.8 x+$ $165.3, r^{2}=0.90$ (where $y=$ mass (g) and $x=$ an approximate measure of time). Plotting the Gompertz conversion values yielded the equation $y=0.4 x-0.01, r^{2}=0.95$, from which we calculated a growth constant of 0.107 . Based on growth data from table 3 in Karhu (1973), G. c. chloropus grew at a rate of $y=4.8 x-3.6, r^{2}=0.96$, where $y=$ mass (g) and $x=$ day. From those growth data we calculated a growth rate of 0.061 from the equation $y=0.3 x-0.4, \quad r^{2}=0.95$, which describes the plot of Gompertz conversion values.

For the two individual G. c. guami for which mass is reported, the 95\% CI (236.1310.9) was lower than that for Hawaiian birds; G. c. meridionalis (95\% CI, 241.3248.7) and female G. c. chloropus (95\% CI, 266.8-275.2) were also lighter than the $\mathrm{Ha}^{-}$ waiian subspecies (see Figure $1 B$ for adult masses of all subspecies). The $95 \%$ CI for G. c. orientalis (181.9-438.1) overlapped that of the Hawaiian subspecies, as did the intervals for female $G$. c. cachinnans (95\% CI, 345.0-353.0) and male G. c. chloropus (95\% CI, 331.9-362.0). Male G. c. cachinnans (95\% CI, 410.7-419.3) and the three G. c. garmani males (95\% CI, 420.0-512.0) were heavier than the Hawaiian birds. Adult measurements of wing cord, tarsus length, and shield + bill length were similar to values reported for other subspecies, with the exception of G. $c$. garmani, which appeared to have longer wings and tarsi than the other subspecies. The nonbody mass data for the different subspecies can be viewed at http://ase.tufts.edu/ biology/labs/reed/res-pub-suppl.html.

Total mass of all feathers was 16.2 and $12.1 \mathrm{~g}$, which made up 3.1 and $3.8 \%$ of the total body mass of the birds $(450 \mathrm{~g}$, and 315 g), respectively. Primaries weighed 2.4 and $2.0 \mathrm{~g}$; secondaries, 0.9 and $0.8 \mathrm{~g}$; rectrices, 0.5 and $0.3 \mathrm{~g}$; and the remaining feathers were 12.3 and $8.9 \mathrm{~g}$.

Hawaiian Moorhen growth appears similar to the development of G. c. chloropus growing in captivity. Based on the data from Karhu (1973), G. c. chloropus would assimilate approximately $80 \%$ of adult body weight by fledging age (40-50 days [Cramp and Simmons 1980]), but this has not been verified for G. c. sandvicensis. The growth constant that we calculated for young Hawaiian Moorhen falls in the range reported for eight rail species (0.041-0.210) (Starck and Ricklefs 1998) and is higher than the growth constant that we calculated for the data reported in Karhu (1973). Unfortunately, not knowing specific ages of young Hawaiian Moorhen precludes us from calculating a more accurate growth constant, so we cannot speculate further about Hawaiian Moorhen growth rate without additional data.

There are six Common Moorhen subspecies currently described whose distributions are exclusively on islands, with the remaining six subspecies found primarily on continents. Although the heaviest birds we found with reported measurements were from a continental subspecies (G. c. garmani), available data do not support the idea of a consistent weight difference between mainland and island subspecies. Adult Hawaiian Moorhens are in the middle of the distribution of Common Moorhen body masses; insufficient data for the five remaining subspecies prevent further comparisons. Similarly, there is extensive overlap among subspecies in other body size measurements. The one notable exception is the mainland subspecies G. c. garmani, which appeared to be larger overall (body mass, 


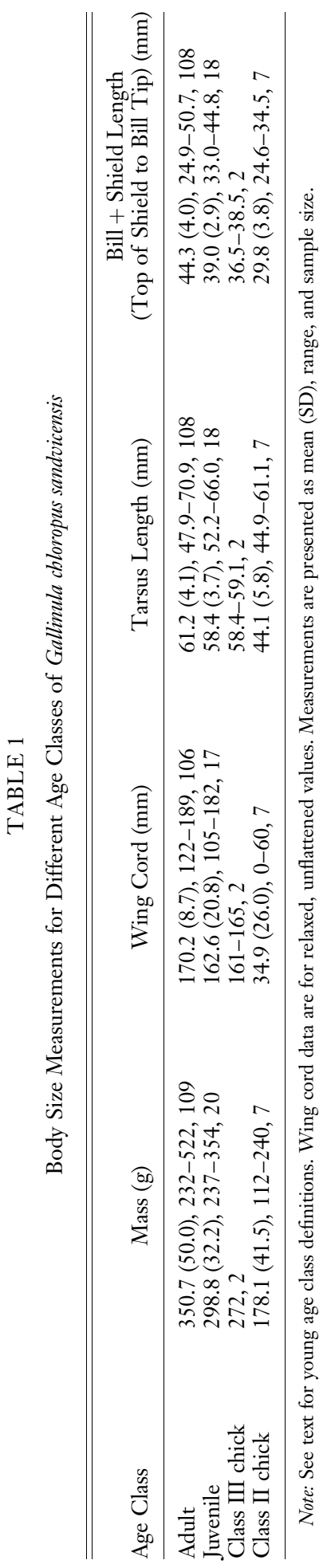

wing and tarsus lengths), although data come from only three individuals. One potential source of variation in body mass is breeding condition. This has been demonstrated in G. c. chloropus (Anderson 1975), but breeding status information was unavailable for the other subspecies, so we were unable to make this additional comparison. In addition, breeding status is complicated in Hawaiian Moorhen because they can breed throughout the year (Byrd and Zeillemaker 1981, Nagata 1983, Chang 1990). Given the extensive range of Common Moorhen subspecies, with distributions on continents and islands, this could be an interesting species for further comparative analyses.

Despite the importance of feathers to avian ecology and their high cost of production (e.g., Lindström et al. 1993, Pryke and Andersson 2005), total feather mass is known for few bird species (Turček 1966). We found Hawaiian Moorhen feather mass to be just below the 4\% reported by Turček (1966) for a single moorhen (likely G. c. chloropus based on the location of the study). This result might be expected for a subspecies, like the Hawaiian Moorhen, that is weakly flighted (sensu McNab 2003, DesRochers et al. 2009). The $4 \%$ also is lower than the $7 \%$ reported for three species of Anatidae (Turček 1966) that, like Hawaiian Moorhen, simultaneously molt their flight feathers (Hohman et al. 1992, DesRochers et al. 2009). It would be very instructive to compare the flight feather mass between this subspecies and a fully migratory subspecies, but data for that comparison are currently lacking.

Knowledge about body mass is important for management of an endangered species such as the Hawaiian Moorhen. The primary conservation implication regarding mass and growth would be if food is limiting, but based on our analyses it is not (DesRochers et al. in press).

\section{ACKNOWLEDGMENTS}

The staff at James Campbell National Wildlife Refuge and B. Casler provided us with technical assistance capturing moorhen, and R. Rameyer and T. Work provided us with 

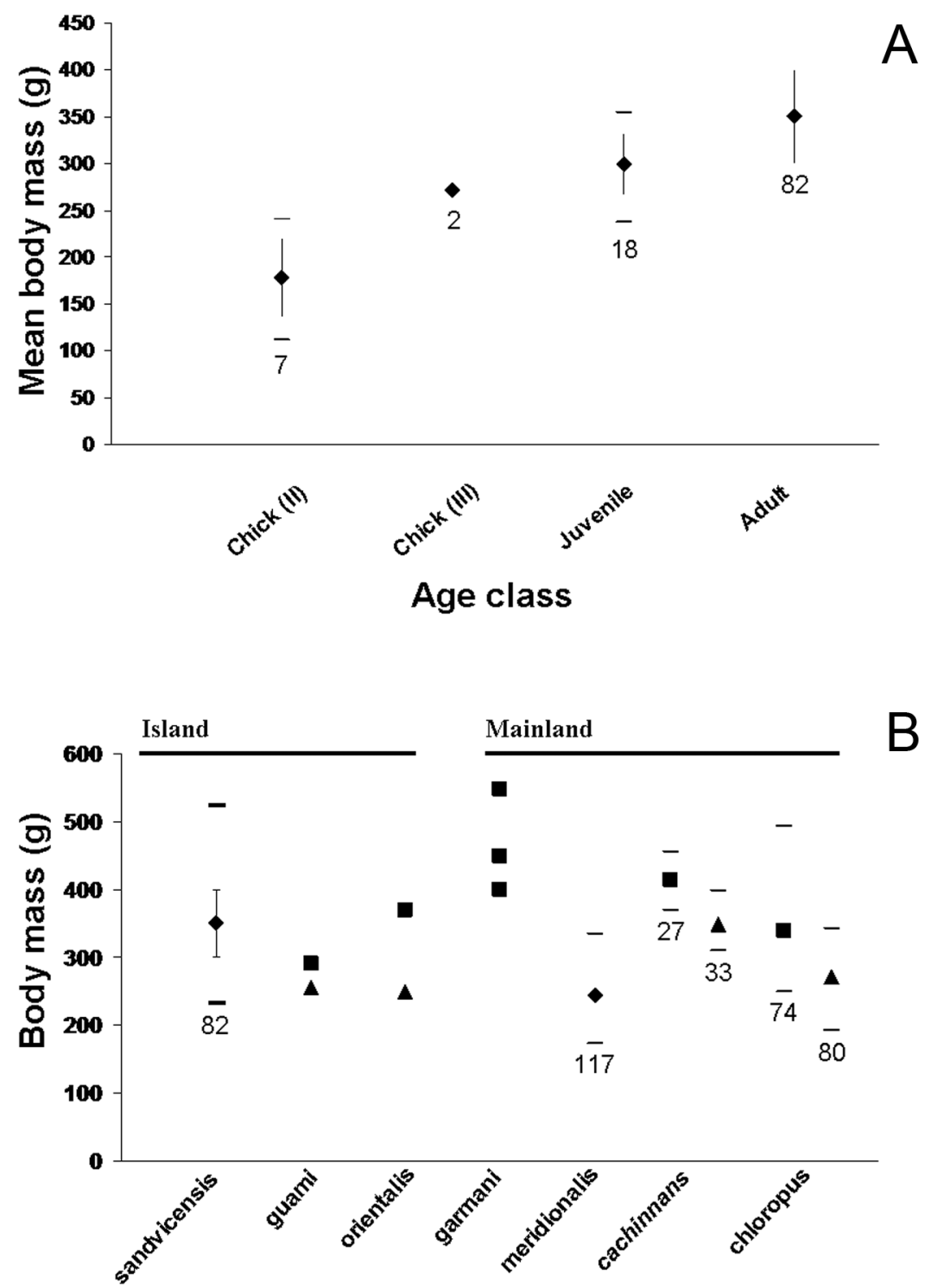

Figure 1. $(A)$ Mean $( \pm \mathrm{SD})$ body mass $(\mathrm{g})$ of young Hawaiian Moorhens; see text for age class definitions. Mean body mass of adult Hawaiian Moorhens is presented for comparison. $(B)$ Mean $( \pm \mathrm{SD})$ body mass $(\mathrm{g})$ of Hawaiian Moorhen (Gallinula chloropus sandvicensis) adults compared with mean adult body mass of other Common Moorhen subspecies, divided by island and mainland residence. Diamonds, unknown sex; squares, male; and triangles, female. Dashes indicate the reported range of body masses. Numbers beneath dashes indicate sample size; symbols without numbers indicate mass of single individuals. Gallinula c. guami and G. c. orientalis data are from Ripley (1977), G. c. garmani data from Taylor (1998), G. c. meridionalis data from Urban et al. (1986), G. c. cachinnans data from Bannor and Kiviat (2002), and G. c. chloropus data from Taylor (1998). 
the moorhen carcasses from which we collected feathers. L. Butler provided technical assistance for classifying flight feather categories. D. Marshall directed our statistical analysis, A. Keyel and B. Tavernia provided feedback on early drafts of the manuscript, and J. Dunning and two anonymous reviewers provided helpful critiques of the manuscript.

\section{Literature Cited}

Anderson, A. 1975. A method of sexing moorhens. Wildfowl 26:77-82.

Bannor, B. K., and E. Kiviat. 2002. Common Moorhen (Gallinula cbloropus). In A. Poole, ed. The birds of North America. Cornell Laboratory of Ornithology, Ithaca, New York. Retrieved from the Birds of North America Online: http://bna.birds.cornell .edu/bna/species/685.

Byrd, G. V., and C. F. Zeillemaker. 1981. Ecology of nesting Hawaiian Common Gallinules at Hanalei, Hawaii. West. Birds 12:105-116.

Chang, P. R. 1990. Strategies for managing endangered waterbirds on Hawaiian $\mathrm{Na}^{-}$ tional Wildlife Refuges. M.S. thesis, University of Massachusetts, Amherst.

Cramp, S., and K. E. L. Simmons. 1980. The birds of the western Palearctic. Vol. 2. Hawks to bustards. Oxford University Press, Oxford.

DesRochers, D. W., L. K. Butler, M. D. Silbernagle, and J. M. Reed. 2009. Observations of molt in an endangered rallid, the Hawaiian Moorhen. Wilson J. Ornithol. 121:148-153.

DesRochers, D. W., S. R. McWilliams, and J. M. Reed. (in press). Evaluating if energy and protein limit abundance of Hawaiian Moorhen. J. Wildl. Manage.

Dunning, J. B. 2008. CRC Handbook of avian body masses. 2nd ed. CRC Press, Boca Raton, Florida.

Gollop, J. B., and W. H. Marshall. 1954. A guide for aging duck broods in the field. Mississippi Flyway Council Technical Section. Northern Prairie Wildlife Research
Center Online. http://www.npwrc.usgs .gov/resource/birds/ageduck/index.htm (Version 14 Nov. 1997).

Guthery, F. S. 1999. Energy-based carrying capacity for quails. J. Wildl. Manage. 63:664-674.

Hohman, W. L., C. D. Ankney, and D. H. Gordon. 1992. Ecology and management of postbreeding waterfowl. Pages 128189 in B. D. J. Batt, A. D. Afton, M. G. Anderson, C. D. Ankney, D. H. Johnson, J. A. Kadlec, and G. L. Krapu, eds. Ecology and management of breeding waterfowl. University of Minnesota Press, Minneapolis.

Johnson, D. H. 1999. The insignificance of statistical significance testing. J. Wildl. Manage. 63:763-772.

Karhu, S. 1973. On the development stages of chicks and adult moorhens Gallinula chloropus at the end of a breeding season. Ornis Fenn. 50:1-17.

Lindström, A., G. H. Visser, and S. Daan. 1993. The energetic cost of feather synthesis is proportional to basal metabolic rate. Physiol. Biochem. Zool. 66:490-510.

$\mathrm{McNab}, \mathrm{B}$. K. 2003. The energetics of New Zealand's ducks. Comp. Biochem. Physiol. A Comp. Physiol. 135:229-247.

Nagata, S. E. 1983. Status of the Hawaiian Gallinule on lotus farms and a marsh on Oahu, Hawaii. M.S. thesis, Colorado State University, Fort Collins.

Pryke, S. R., and S. Andersson. 2005. Experimental evidence for female choice and energetic costs of male tail elongation in redcollared widowbirds. Biol. J. Linn. Soc. 86:35-43.

Ripley, S. D. 1977. Rails of the world. M. F. Feheley Publishers, Toronto.

Snedecor, G. W., and W. G. Cochran. 1989. Statistical methods. 8th ed. Iowa State University Press, Ames.

Starck, J. M., and R. E. Ricklefs. 1998. Avian growth rate data set. Pages 381-415 in J. M. Starck and R. E. Ricklefs, eds. Avian growth and development. Oxford University Press, New York.

Taylor, B. 1998. Rails. Yale University Press, New Haven, Connecticut. 
Turček, F. J. 1966. On plumage quantity in birds. Ekol. Pol. Ser. A 14:617-634.

Urban, E. K., C. H. Fry, and S. Keith. 1986. The birds of Africa. Vol. 2. Academic Press, London.
Wilcove, D. S., D. Rothstein, J. Dubow, A. Phillips, and E. Losos. 1998. Quantifying threats to imperiled species in the United States. BioScience 48:607-615. 
